\title{
Migraine treatment: the doors for the future are open, but with caution and prudence
}

\author{
Tratamento da migrânea: as portas para o futuro estão abertas, mas com cuidado e \\ parcimônia
}

\author{
Abouch V. Krymchantowski', Ana Gabriela Ferreira Krymchantowski', Carla da Cunha Jevoux ${ }^{1}$
}

\begin{abstract}
Migraine is a burdensome disorder. Current treatments are far from ideal. Recent knowledge has been indicating targets whose antagonism may improve efficacy. It is particularly true with the calcitonin gene-related peptide (CGRP) and the monoclonal antibodies anti-CGRP can interfere with this pathway and decrease the frequency of migraine attacks. Erenumab, fremanezumab and galcanezumab have recently been approved and eptinezumab is likely to be, soon. Although efficacy figures were not spectacular, tolerability and potential higher adherence were noteworthy. However, caution must be exercised. The time frame after the studies was limited to three years and dose administration was restricted to three-monthly doses. The CGRP is present throughout the human body and migraine is a life-long disease, often requiring treatment for decades. It is not known whether this favorable profile can be maintained or will be safe in pregnant women or adolescents. In addition, there were deaths during the studies, which may have happened without a clear relationship. New treatments are welcome, but caution is warranted.
\end{abstract}

Keywords: Migraine; therapeutics; upcoming treatments; antibodies, monoclonal.

\section{RESUMO}

A migrânea é incapacitante. Os tratamentos atuais apresentam resultados abaixo do desejado. O conhecimento atual indica alvos nos quais o bloqueio pode melhorar a eficácia do tratamento. Isso é mais claro com o peptídeo relacionado ao gene da calcitonina (CGRP) e anticorpos monoclonais contra este peptídeo ou seu receptor interferem com a fisiopatologia migranosa e reduzem a frequência da cefaleia. Erenumab, fremanezumab e galcanezumab já foram aprovados. Eptinezumab o será em breve. Embora a eficácia não tenho sido espetacular, a boa tolerabilidade e melhor adesão foram notáveis. No entanto, cautela deve ser empregada. Os estudos se limitaram a observar os pacientes por até três anos e com três doses mensais seguidas. Existe CGRP em todo o organismo e a migrânea é uma doença crônica, não raro requerendo tratamento por décadas. Não se sabe se a tolerabilidade favorável manter-se-á por anos ou em grávidas e adolescentes. Também houve mortes durante os estudos, mesmo sem ligação comprovada. Novos tratamentos são bem-vindos, mas cautela é necessária neste momento.

Palavras-chave: Enxaqueca; terapêutica; novos tratamentos; anticorpos monoclonais.

Migraine is a highly prevalent, disabling disorder. It has a substantial impact on patient's lives and promotes a large global burden to society ${ }^{1}$. Serendipity is a term that describes current available treatments, especially regarding prevention ${ }^{2}$. The drugs used up to now are far from that desired by patients and treating physicians and have been found to be effective by chance, when used for other pathological conditions. However, low efficacy figures and unfavorable tolerability profiles make adherence poor and the treatment a challenge ${ }^{2,3}$.

Knowledge about migraine pathophysiology has been evolving over the last decades, but it is still limited ${ }^{4,5}$. However, neuromediators of the complex process involved in migraine headache attacks, such as the calcitonin gene-related peptide
(CGRP), have become protagonists of this burdensome disease that costs too much to humanity, and the antagonism of CGRP may represent a key path for improving the sufferers' lives ${ }^{4,5}$.

The CGRP is a 37-amino acid peptide present throughout the human body. Sensory neurons, myelinated and unmyelinated fibers involved in pain transmission, either at the dorsal root ganglia and trigeminal ganglia, represent some of the structures where CGRP are densely present, not only in the central nervous system in the thalamus, hypothalamus and cerebellum, but in the peripheral nervous system as well ${ }^{4,5}$. The peptide is a potent vasodilator, also encountered in joints, kidneys, adrenal glands, pancreas and throughout the arterial system in the smooth muscle cell layer ${ }^{4,5}$.

${ }^{1}$ Centro de Avaliação e Tratamento da Dor de Cabeça do Rio de Janeiro, Rio de Janeiro RJ, Brasil.

Abouch V. Krymchantowski (iD) https://orcid.org/0000-0001-8164-3507

Correspondence: Abouch V. Krymchantowski Centro de Avaliação e Tratamento da Dor de Cabeça do Rio de Janeiro; Rua Siqueira Campos, 43 / 1002 Copacabana; 22031-071 Rio de Janeiro RJ, Brasil; E-mail: abouchkrym@uol.com.br

Conflict of interest: There is no conflict of interest to declare.

Received 13 August 2018; Received in final form 19 October 2018; Accepted 21 November 2018. 
The receptor to which CGRP binds has two subunits and is described as a G-protein coupled receptor, comprising an activity-modifying protein 1 subunit known as RAMP1 and a calcitonin receptor-like subunit ${ }^{6}$. The CGRP has been attracting attention as a core substance in migraine over the last 20 years. Intravenous infusion of CGRP triggers attacks in migraineurs that are indistinguishable from spontaneous attacks; serum CGRP levels are elevated in episodic migraine, even interictally, and CGRP concentrations in blood from the jugular veins rise during migraine attacks, while its serum level decreases with symptomatic relief ${ }^{6,7}$.

Different molecules can indeed antagonize CGRP or its receptor. Over the last few decades, potential agents for the acute treatment of migraine acting on the CGRP receptor have been studied ${ }^{4,5,7,8}$. Although true efficacy was demonstrated with several antagonists, toxicity, especially hepatotoxicity, has impeded their approval, and resulted in the interruption of the release of upcoming medications such as telcagepant ${ }^{8,9}$. The concept of a drug antagonizing the CGRP receptor and thus representing a useful tool for treating migraine attacks was never really abandoned. In addition, biological options such as monoclonal antibodies anti-CGRP or the CGRP receptor began to be developed and three have recently been approved by the rigorous $\mathrm{FDA}^{7,8,10}$.

These indisputable facts point to the usefulness and acceptable tolerability of this treatment path, initiated nearly 15 years ago.

\section{UPCOMING THERAPIES}

Three CGRP receptor antagonists and one anti-CGRP monoclonal antibody are close to being released. Erenumab, the only monoclonal antibody against the CGRP receptor and two monoclonal antibodies against the peptide CGRP itself, fremanezumab and galcanezumab, were approved in 2018 and will be discussed later .

The efficacy and tolerability of the small molecule acting as a CGRP receptor antagonist known as ubrogepant was evaluated in a double-blind, placebo-controlled study of 834 participants who treated one migraine attack with $1 \mathrm{mg}, 10 \mathrm{mg}$, $25 \mathrm{mg}, 50 \mathrm{mg}, 100 \mathrm{mg}$, or placebo in a 1:1 ratio ${ }^{9}$. The primary endpoints were freedom from pain and headache response at two hours. A total of 527 subjects received ubrogepant and 113 received a placebo. A positive response trend in the proportion of participants achieving two-hour pain freedom was demonstrated $(\mathrm{p}<0.001)$. Ubrogepant $100 \mathrm{mg}$ was significantly superior to placebo for two-hour pain freedom ( $25.5 \%$ vs. $8.9 \%$ ), but not for two-hour headache response. Tolerability was similar between ubrogepant and placebo $^{11}$.
Despite the positive efficacy outcome, potential liver toxicity must be ruled out. There were patients with a substantial alanine aminotransferase increase reaching five to ten times the normal range ${ }^{12}$.

Rimegepant has been studied in a phase 2 trial comparing different doses $(75 \mathrm{mg}, 150 \mathrm{mg}$ and $300 \mathrm{mg}$ ) with placebo. Pain-free rates at two hours varied between $29.7 \%$ to $32.9 \%$, while placebo rates were $15.3 \%(\mathrm{p}<0.002)$. Although it was comparable with $100 \mathrm{mg}$ sumatriptan regarding painfree rates at two hours, it was well tolerated with no serious adverse events. A review of phase 3 data covered 1,072 patients ${ }^{8}$. One study revealed the superiority of rimegepant $75 \mathrm{mg}$ over placebo regarding two-hour pain freedom (19.2\% vs. $14.2 \%, \mathrm{p}<0.03)$. Another study comparing rimegepant and placebo demonstrated similar efficacy results with $19.6 \%$ vs. $12 \%(\mathrm{p}<0.001)^{8}$. At the time of writing this review, there were no published data on rimegepant and only press releases were available.

Previously Merck's MK-8031, atogepant is currently designated AGN-241689 and has been studied for episodic migraine prevention but not for acute attacks. Doses of 10 $\mathrm{mg}, 30 \mathrm{mg}$ and $60 \mathrm{mg}$ in different posologies are been compared to placebo and data is still unavailable ${ }^{1, *}$. Data on atogepant is available only through personal communications, as no data has been published so far.

Monoclonal antibodies represent an interesting way to treat migraine. Because of their peculiar characteristics of restricted tissue penetrance, very long half-life and highly selective affinity for the CGRP or its receptor, they have become the center of the upcoming arsenal against the suffering imposed by migraine, although CGRP nerve endings are extraluminal in most tissues, which may impair and limit their efficacy ${ }^{4,5}$. Erenumab was recently approved for the preventive treatment of migraine. It is the only one of the four monoclonal antibodies for migraine that acts on the CGRP receptor and not on the CGRP itself ${ }^{4,5}$. Fremanezumab and galcanezumab were approved recently and act on the CGRP itself ${ }^{8}$.

For erenumab, patients with episodic migraine were randomized to receive doses of $7 \mathrm{mg}, 14 \mathrm{mg}, 70 \mathrm{mg}$ or placebo, subcutaneously, every four weeks for 12 weeks. The patients studied had a baseline of 4-14 headache days in four weeks. The change in number of migraine days during weeks 9-12, compared to baseline, was significantly superior for the 70 $m g$ dose $(-3.4 \text { vs. }-2.3 \text { days, } \mathrm{p}=0.021)^{13}$.

Erenumab was also studied for chronic migraine prevention. In a multicenter, phase 2 , randomized, doubleblind, placebo-controlled trial, 667 patients received either $70 \mathrm{mg}, 140 \mathrm{mg}$ or placebo in two $1 \mathrm{ml}$ subcutaneous injections at the study centers on day one, four weeks and eight weeks later. The primary outcome evaluated was the mean

\footnotetext{
* Rapoport A. Personal Communication during Editorial Board Meeting of the Headache. The Journal for Head and Facial Pain. June 29th $12: 30$ PM. 2018. San Francisco Marriot Hotel. California. US.
} 
change in monthly migraine days from the baseline phase to the last four weeks of the 12-week treatment phase. Both doses reduced migraine days significantly more than placebo (-6.6 vs. $-4.2 ; \mathrm{p}<0.0001)$. Interestingly, this study had a similar percentage of patients who had failed previously on one or two drugs for prevention, either topiramate or on botulinum toxin $\mathrm{A}^{14}$.

Two phase 3 pivotal registration trials were published in the last two years ${ }^{15,16}$. The Study to Evaluate the Efficacy and Safety of Erenumab in Migraine Prevention (STRIVE) trial assessed patients with 4-14 migraine days/month and was designed as a six-month study with three arms. The total number of patients studied was 955, with 319 receiving 140 mg erenumab, 319 receiving placebo, and 317 receiving 70 mg erenumab, in monthly subcutaneous injections for six months. As for the primary endpoint of reduction in mean migraine days per month compared with the previous threemonth baseline period, the $140 \mathrm{mg}$ group had a reduction of 3.7 days, the $70 \mathrm{mg}$ group of 3.2 days, and the placebo group of 1.8 days $(\mathrm{p}<0.001$ for each dose vs. placebo). The secondary endpoints of $\geq 50 \%$ responder rate in mean monthly migraine days, days with use of migraine-specific medications and changes in the score of physical impairment and everyday activities, were all significantly better than placebo for both the $70 \mathrm{mg}$ and $140 \mathrm{mg}$ doses ${ }^{15}$.

Another pivotal study, over a three-month period, evaluated the erenumab dose of $70 \mathrm{mg}$, and placebo in 570 patients. The primary endpoint of this trial was also the change of mean monthly migraine days at 9-12 weeks compared with the baseline. Again, erenumab promoted a mean reduction of 2.9 days vs. 1.8 days of the placebo group $(p<0.001)$. In both studies, there were no serious related adverse events, and injection-site reactions and/or pain were the most observed effects in $3.2 \%$ to $6 \%$ of the active therapy groups. Some degree of nonincapacitating arthralgia and constipation were also found with erenumab in the STRIVE study ${ }^{16}$.

Fremanezumab or TEV-48215 or LBR-101 from TEVA, was the second monoclonal antibody approved for clinical use by the FDA. It was studied in trials for episodic migraine, high-frequency episodic migraine or chronic migraine. In a trial for high-frequency episodic migraine, the doses were different and patients with 8-14 headache days during a fourweek baseline period were randomized to receive placebo, $675 \mathrm{mg}$ ( followed by two placebo doses) or $225 \mathrm{mg}$ every four weeks during the study time frame of 12 weeks $^{17}$. The monoclonal antibody and the placebo were administered in subcutaneous injections. Efficacy was measured in the changing number of migraine days during the weeks 9-12; therefore, the third four-week treatment period was compared with the baseline. Both doses showed a significantly greater reduction compared with placebo. The use of monthly doses of $225 \mathrm{mg}$ showed a reduction of 6.27 migraine days in the treatment group compared with 3.46 days in the placebo group; a difference of 2.81 days $(\mathrm{p}<0.0001)$, while $675 \mathrm{mg}$ resulted in a reduction of 6.09 migraine days in the treatment group compared with 3.46 days in the placebo group; a difference of 2.64 days ( $\mathrm{p}<0.0001)$. Interestingly, this study did not exclude preventive medications use, which had to be in stable doses for two months prior to the inclusion ${ }^{17}$.

In another study, with the acronym HALO, representing a pivotal phase 3 registration study for the prevention of episodic migraine, the mean change in number of migraine days and not only on headache days, was evaluated in 875 patients (742 women; 133 men) with a mean age of 41.8 years. It revealed a reduction from 8.9 days to 4.9 days in those who received $225 \mathrm{mg}$ per month (three doses) vs. 9.2 days to 5.3 days in patients who received a single dose of $675 \mathrm{mg}$, compared with 9.1 days to 6.5 days in the placebo group. The difference between monthly dosing vs. placebo was -1.5 days $(p<0.001)$ and between a single higher dose vs. placebo was -1.3 days $(\mathrm{p}<0.001)^{17}$.

The tolerability was similar between the placebo and treatment groups. Nearly $2 \%$ of the patients in each of the studied groups discontinued treatment because of adverse events, which were erythema (three patients) and two patients each with induration at injection sites, depression, anxiety or diarrhea. Liver function abnormalities were observed in two participants on the monthly doses, one patient on the quarterly dose and one placebo individual. Although one death occurred, with the patient having received the higher dose of fremanezumab, apparently it was caused by diphenhydramine overdose and suicide ${ }^{18}$.

Fremanezumab has also been studied in chronic migraine prevention ${ }^{19}$. The patients were randomized to either the monoclonal antibody in an initial loading dose of $675 \mathrm{mg}$, followed by two monthly doses of $225 \mathrm{mg}$, or three doses of $900 \mathrm{mg}$, or placebo. The doses were given every four weeks for 12 weeks. The mean reduction in headache hours, of any intensity, during the weeks 9-12 was significantly greater compared with placebo, for all three dosages in the patient groups. The patients who received three doses of $900 \mathrm{mg}$ had -67.5 vs. -37.1 of headache hours - a difference of 30.4 hours fewer headaches, $p=0.0057$; while the difference between those having received $675 \mathrm{mg} / 225 \mathrm{mg}$ and $225 \mathrm{mg}$ was -59.8 vs. -37.1 headache hours-a difference of 22.7 headache hours, $p=0.038$. Again, these patients could have been using up to two preventive agents simultaneously, but no adjustments in the doses for at least three months were allowed. In addition, the mean number of headache days per month at baseline was 16, therefore, it is not possible to make comparisons with daily or near-daily headache sufferers ${ }^{19}$.

In another phase 3 trial of fremanezumab, representing a pivotal registration study for the prevention of chronic migraine, 1,130 patients were randomized to receive placebo (375 patients); quarterly with $675 \mathrm{mg}$ as a loading dose at baseline followed by two doses of placebo at weeks four and eight (376 patients); and monthly with $675 \mathrm{mg}$ as a loading dose at baseline and $225 \mathrm{mg}$ at weeks four and 
eight (379 patients) ${ }^{20}$ at 132 different sites. The primary endpoint was the change in headache days, from a baseline of at least four consecutive hours of headache pain, with a peak severity of moderate intensity or headache days in which migraine-specific medications were used, at week $12^{20}$. The baseline monthly frequency of migraine days was 16.2 days for the quarterly dose group, 16 days for the monthly dose group and 16.4 days for the placebo group. The patients who received fremanezumab monthly showed a reduction in migraine headache days of $4.6 \pm 0.3$. Those having received fremanezumab quarterly had a reduction of $4.3 \pm 0.3$ days and the 375 placebo patients showed a 2.5 \pm 0.3 reduction in headache days ( $p<0.001$ for both comparisons with placebo). Secondary endpoints of this study also showed better performance for the active monoclonal antibody patients. The $\geq 50 \%$ responder rate of reduction in monthly migraine days was, respectively, $38 \%$ for the quarterly dose patients, $41 \%$ for the monthly dose patients and $18 \%$ for the placebo users $(\mathrm{p}<0.001$ for both doses vs. placebo). Disability was also evaluated as a secondary endpoint and showed, through the Headache Impact Test (HIT-6), reductions of 4.5 points for the placebo patients vs. reductions of 6.8 and 6.4 points, respectively for the monthly and quarterly patients $(p<0.001$ for both doses vs. placebo $)^{20}$.

The most common adverse event was injection-site reaction for the monoclonal antibody users. However, although no differences were encountered among active antibodies and placebo regarding elevation of liver function tests, 10 patients (five in each dose group) compared with three placebo patients (not statistically significant) demonstrated some degree of elevation of alanine transaminase or aspartate aminotransferase or total bilirubin levels ${ }^{20}$.

The third approved monoclonal antibody, galcanezumab or LY2951742 from Lilly, was studied recently in two phase 3 trials known as EVOLVE-1 and -2 for the preventive treatment of migraine ${ }^{21,22}$. The first trial was a double-blind, randomized (2:1:1), placebo-controlled comparison between placebo and galcanezumab $120 \mathrm{mg}$ or $240 \mathrm{mg}$. The patients received monthly subcutaneous doses for six months and were followed up for five months after their last injection. The study involved 90 centers in North America and had a clinic-based design. Participants were aged 18 to 65 years with a minimum of a one-year history of migraine and 4-14 migraine headache days per month. A total of 1,671 patients were assessed, with the inclusion of 858 in the intent-to-treat population. No other preventive medications were allowed during the study ${ }^{21}$.

The primary outcome was the mean change in number of monthly migraine headache days during the treatment period. Secondary endpoints were a frequency reduction of at least $50 \%$, of at least $75 \%$, and of $100 \%$ in the same parameter. In addition, migraine headache days with acute medication use, scores from the Migraine-Specific Quality of Life questionnaire and Patient Global Impression of Severity, as well as the Migraine Disability Assessment were also compared between goups ${ }^{21}$.

Among the 858 patients included (mean age, 40.7 years; 718 women [83.7\%]), the primary endpoint was achieved for both galcanezumab doses and $81.9 \%$; $(n=718)$ of the studied patients completed the trial. The active treatment significantly reduced monthly migraine headache days by 4.7 days (120 mg) and by 4.6 days (240 mg) compared with placebo (2.8 days) (both $\mathrm{p}<0.001)$. Regarding secondary endpoints, galcanezumab was significantly superior to placebo, although no differences between $120 \mathrm{mg}$ and $240 \mathrm{mg}$ doses were encountered ${ }^{21}$.

The EVOLVE-2 study was also double-blind, with 915 intent-to-treat patients randomized to receive monthly galcanezumab $120 \mathrm{mg}(\mathrm{n}=231)$ or $240 \mathrm{mg}(\mathrm{n}=223)$ or placebo $(n=461)$ subcutaneous injections over six months ${ }^{22}$. The primary endpoint was a mean change from baseline in monthly migraine headache days. Key secondary endpoints were $\geq 50 \%, \geq 75 \%$, and $100 \%$ response rates and reduction of monthly migraine headache days with acute migraine medication use. The Role Function-Restrictive score of the Migraine-Specific Quality of Life questionnaire and the Patient Global Impression of Severity rating were assessed and compared as well ${ }^{22}$.

The mean age of the study population was 41.9 years, and the population was largely female (85.4\%), white $(70.3 \%)$, and North American (48.7\%) or European (26.3\%). At baseline, approximately $66.9 \%$ of the patients had eight or more migraine headache days per month. The majority (65.5\%) of the patients had prior experience with migraine preventive treatments and $14.3 \%$ of them had previously failed on two or more preventive medications ${ }^{22}$.

Monthly migraine headache days were reduced by 4.3 and by 4.2 days with galcanezumab $120 \mathrm{mg}$ and $240 \mathrm{mg}$. Placebo reduced headache days by 2.3 . The group differences $(95 \% \mathrm{CI})$ compared with placebo were $2.0(-2.6,-1.5)$ and $1.9(-2.4,-1.4)$ headache days, respectively. Both doses were superior to placebo for all key secondary endpoints and the occurrence of injection site reactions was the most common adverse event. Both galcanezumab doses had significantly more injection site reactions and injection site pruritus, but the $240 \mathrm{mg}$ group had significantly more injection site erythema than the placebo group ${ }^{22}$.

Eptinezumab, known as ALD-403 from Alder is the only monoclonal antibody administered intravenously and was initially studied in a single dose of $1000 \mathrm{mg}$. It is also used for the prevention of episodic migraine and was compared with placebo in a randomized, double-blind, exploratory, proof-ofconcept phase 2 trial. In the study, at 26 centers, 163 patients (18-55 years) received either ALD403 $(n=81)$ or placebo $(n$ = 82). The patients had 5-14 migraine days per 28-day period and were randomly assigned (1:1). The primary objective was to assess safety at 12 weeks after infusion. The primary 
efficacy endpoint was the change from baseline in the frequency of migraine days at weeks 5-8. Patients were followed up until 24 weeks for exploratory safety and efficacy analyses, which were evaluated by intention to treat ${ }^{23}$.

The mean change in migraine days between baseline and weeks 5-8 was -5.6 for the ALD403 group compared with -4.6 for the placebo group (difference -1.0, 95\%CI -2.0 to 0.1 ; $\mathrm{p}=0.0306)$. Adverse events were experienced by $46(57 \%)$ of 81 patients in the ALD403 group and by 43 (52\%) of 82 in the placebo group. The most frequent adverse events were fatigue (3 [4\%] in both groups), upper respiratory tract infection (ALD403 group 7 (9\%) vs. placebo group 6 (7\%)), arthralgia (4 [5\%] vs. $1[1 \%])$, urinary tract and back pain (4 [5\%] vs. $3[4 \%]$ ). There were no differences in vital signs or laboratory safety data between the two treatment groups ${ }^{23}$.

The phase 3 pivotal migraine prevention trials were known as the Prevention of Migraine via Intravenous eptinezumab Safety and Efficacy (PROMISE-1 and -2). In PROMISE-1, 888 migraineurs with 4-14 migraine days per month were randomized to receive quarterly intravenous infusions of either placebo or eptinezumab doses of $30 \mathrm{mg}, 100 \mathrm{mg}$ or $300 \mathrm{mg}$. The reduction in migraine days over 12 weeks was the primary endpoint and the baseline frequency among groups was similar, reaching 8.4 to 8.7 days. The $300 \mathrm{mg}$ dose reduced migraine days by 4.3 compared with a reduction of 3.2 in the placebo group and a reduction of 4 and 3.9 migraine days, respectively, for the $30 \mathrm{mg}$ and $100 \mathrm{mg}$ doses $(\mathrm{p}<0.0001$ for $300 \mathrm{mg}$ vs. placebo; 0.0046 for $30 \mathrm{mg}$ vs. placebo and 0.0182 for $100 \mathrm{mg}$ vs. placebo ${ }^{24}$.

The $\geq 75 \%$ and $\geq 50 \%$ responder rates for weeks $1-4$ and 1-12 were also evaluated and compared between groups. For the weeks $1-4,31.5 \%$ of the $300 \mathrm{mg}$ patients vs. $20.3 \%$ of the placebo group showed a responder rate of higher than $75 \%$ ( $p=0.0066$ ). In addition, the results of long-term follow-up after four infusions showed over $51 \%$ of patients who received the $300 \mathrm{mg}$ dose achieving $\geq 75 \%$ reduction in days of migraine after the $3^{\text {rd }}$ and $4^{\text {th }}$ infusions ${ }^{24}$.

Regarding adverse events, upper respiratory infection occurred in $11 \%$ of the $30 \mathrm{mg}, 10 \%$ in the $100 \mathrm{mg}$, $10 \%$ in the $300 \mathrm{mg}$ patient groups and in $7 \%$ of the placebo groups. Nasopharyngitis occurred in $6 \%$ of the $30 \mathrm{mg}$ and $300 \mathrm{mg}$ groups, as well as in $8 \%$ of the $100 \mathrm{mg}$ and $5 \%$ of the placebo groups.

The second pivotal epitnezumab study, was the PROMISE-2, which was designed to evaluate the efficacy of epitnezumab in the prevention of chronic migraine $e^{25}$. The patients included had $\geq 15$ to 26 headache days per month with at least eight migraine days. They received either epitnezumab $100 \mathrm{mg}, 300 \mathrm{mg}$ or placebo in quarterly intravenous injections. Baseline migraine frequency was 16.1 days for the active antibody groups and 16.2 for the placebo group. The primary endpoint of this trial was the change in mean migraine days per month during weeks 1-12 and the observed reductions were, respectively, -8.2 days for the $300 \mathrm{mg}$ group,
-7.7 for the $100 \mathrm{mg}$ group and -5.6 days for the placebo group $(\mathrm{p}<0.0001 \text { for both doses vs. placebo })^{25}$.

Nasopharyngitis was the most common adverse event, reported in $6 \%$ of those receiving $300 \mathrm{mg}$ and in $4 \%$ of those receiving placebo and $100 \mathrm{mg}$ eptinezumab. In addition, dizziness occurred in $1 \%$ of the placebo and $100 \mathrm{mg}$ groups and $2 \%$ of the $300 \mathrm{mg}$ group. No deaths were reported in any eptinezumab study ${ }^{25}$.

\section{COMMENTS}

Decreasing migraine headache frequency or headache days by at least $50 \%$ is the clinical trial endpoint recommended by the Clinical Trials Subcommittee of the International Headache Society, although it is below the level desired by patients and treating physicians, struggling to get or provide relief $^{26}$. However, less than half the patients are fortunate enough to achieve this reduction, even with the current FDA-approved pharmacological agents for migraine prevention, such as topiramate, sodium divalproate and propranolol ${ }^{2}$. In truth, there are patients who perform well with a rational combination of drugs but may not adhere satisfactorily due to tolerability issues with the available medications ${ }^{27}$. It seems clear that recently-approved antibody treatments are better in terms of adverse events profiles and posology, but still have limited efficacy to achieve at least $50 \%$ reduction in migraine frequency ${ }^{4,8,10}$.

In addition, one might argue on the long-term safety of these treatments options, especially because migraine is a lifelong disease that may impose functional disability and suffering from early life, often requiring treatment for decades ${ }^{10}$. Additionally, we do not yet know whether the drugs will perform safely in patients who become pregnant during or after treatment and whether repetitive use throughout the lifespan will be necessary or indicated. Although the four monoclonal antibodies presented attractive tolerability profiles in phase 2 and phase 3 trials, one cannot forget the three deaths during the studies with fremanezumab and erenumab. One patient died from chronic obstructive pulmonary disease 69 days after receiving $675 \mathrm{mg}$ of fremanezumab in a trial for chronic migraine prevention. Another patient committed suicide 109 days after receiving $675 \mathrm{mg}$ of fremanezumab for episodic migraine and a third patient died of an arteriosclerosis event after receiving $70 \mathrm{mg}$ of erenumab for the prevention of episodic migraine. Despite the possible coincidence and the lack of clear relationship between monoclonal antibodies and the fatal events, we can't deny the possibility of cardiovascular ischemia and even myocardial infarction when CGRP is suppressed, despite recent evidence of safety, even in a stable angina patient ${ }^{28}$.

Additionally, airway homeostasis and the proper activity of the pancreas or adrenal glands are also related to the presence of CGRP throughout human tissues. These facts, although 
possibly unrelated, may bring back the frustration experienced with the setbacks of CGRP receptor antagonists such as telcagepant, otherwise a promising nearly-launched drug'.

There is no doubt that patients and their doctors are in a tireless quest to reduce migraine disability and receive/prescribe more comprehensive therapies that could be mechanism-based or precision-designed for migraine, therefore provoking fewer disturbing effects or at least providing better outcome figures. We strongly believe that the combination between already-available pharmacological agents and monoclonal antibodies will represent the most efficacious approach, despite the lack of evidence that will remain for a long period of time. However, caution must be exercised at this time. Further studies are required to evidence the adverse side effect potential, as well as long-term safety of these upcoming medications and antibodies. The new era of migraine treatment is here and is more than welcome, but enthusiasm has always to hang on safety.

\section{References}

1. GBD 2016 Disease and Injury Incidence and Prevalence Collaborators. Global, regional, and national incidence, prevalence, and years lived with disability for 328 diseases and injuries for 195 countries, 1990-2016: a systematic analysis for the Global Burden of Disease Study 2016. Lancet. 2017 Sep;390(10100):1211-59. https://doi.org/10.1016/S0140-6736(17)32154-2

2. Estemalik E, Tepper S. Preventive treatment in migraine and the new US guidelines. Neuropsychiatr Dis Treat. 2013;9:709-20. https://doi.org/10.2147/NDT.S33769

3. González-Hernández A, Marichal-Cancino BA, MaassenVanDenBrink A, Villalón CM. Side effects associated with current and prospective antimigraine pharmacotherapies. Expert Opin Drug Metab Toxicol. 2018 Jan;14(1):25-41. https://doi.org/10.1080/17425255.2018.1416097

4. Tso AR, Goadsby PJ. Anti-CGRP monoclonal antibodies: the next era of migraine prevention? Curr Treat Options Neurol. 2017 Aug;19(8):27. https://doi.org/10.1007/s11940-017-0463-4

5. Messina R, Goadsby PJ. CGRP - a target for acute therapy in migraine: clinical data. Cephalalgia. 2018 Jan. https://doi.org/10.1177/0333102418768095

6. McLatchie LM, Fraser NJ, Main MJ, Wise A, Brown J, Thompson N, et al. RAMPs regulate the transport and ligand specificity of the calcitonin-receptor-like receptor. Nature. 1998 May;393(6683):3339. https://doi.org/10.1038/30666

7. Edvinsson L, Ho TW. CGRP receptor antagonism and migraine. Neurotherapeutics. 2010 Apr;7(2):164-75. https://doi.org/10.1016/j.nurt.2010.02.004

8. Tepper SJ. History and review of anti-Calcitonin Gene-Related Peptide (CGRP) Therapies: From Translational Research to Treatment [Epub ahead of print] [ Review]. Headache. 2018 Nov;58 Suppl 3:23875. https://doi.org/10.1111/head.13379

9. Ho TW, Connor KM, Zhang Y, Pearlman E, Koppenhaver $J$, Fan X, et al. Randomized controlled trial of the CGRP receptor antagonist telcagepant for migraine prevention. Neurology. 2014 Sep;83(11):958-66. https://doi.org/10.1212/WNL.0000000000000771

10. Loder EW, Robbins MS. Monoclonal antibodies for migraine prevention. Progress, but not a panacea. JAMA. 2018 May;319(19):1985-7. https://doi.org/10.1001/jama.2018.4852

11. Voss T, Lipton RB, Dodick DW, Dupre N, Ge JY, Bachman R, et al. A phase Illb randomized, double-blind, placebo-controlled trial of ubrogepant for the acute treatment of migraine. Cephalalgia. 2016 Aug;36(9):887-98. https://doi.org/10.1177/0333102416653233

12. Trugman J, Finnegan M, Lipton R, et al. Efficacy, safety, and tolerability of ubrogepant for the acute treatment of migraine: results from a single attack phase II study. In: American Academy of Neurology Meeting, Los Angeles, April 24, 2018.

13. Sun H, Dodick DW, Silberstein S, Goadsby PJ, Reuter U, Ashina $M$, et al. Safety and efficacy of AMG 334 for prevention of episodic migraine: a randomised, double-blind, placebo- controlled, phase 2 trial. Lancet Neurol. 2016 Apr;15(4):382-90. https://doi.org/10.1016/S1474-4422(16)00019-3

14. Tepper S, Ashina M, Reuter U, Brandes JL, Doležil D, Silberstein S, et al. Safety and efficacy of erenumab for preventive treatment of chronic migraine: a randomised, double-blind, placebocontrolled phase 2 trial. Lancet Neurol. 2017 Jun;16(6):425-34. https://doi.org/10.1016/S1474-4422(17)30083-2

15. Goadsby PJ, Reuter U, Hallström Y, Broessner G, Bonner JH, Zhang F, et al. A controlled trial of erenumab for episodic migraine. N Engl J Med. 2017 Nov;377(22):2123-32. https://doi.org/10.1056/NEJMoa1705848

16. Dodick DW, Ashina M, Brandes JL, Kudrow D, Lanteri-Minet M, Osipova V, et al. ARISE: A Phase 3 randomized trial of erenumab for episodic migraine. Cephalalgia. 2018 May;38(6):1026-37. https://doi.org/10.1177/0333102418759786

17. Bigal ME, Dodick DW, Rapoport AM, Silberstein SD, Ma Y, Yang $\mathrm{R}$, et al. Safety, tolerability, and efficacy of TEV-48125 for preventive treatment of high-frequency episodic migraine: a multicentre, randomised, double-blind, placebo-controlled, phase 2b study. Lancet Neurol. 2015 Nov;14(11):1081-90. https://doi.org/10.1016/S1474-4422(15)00249-5

18. Dodick DW, Silberstein SD, Bigal ME, Yeung PP, Goadsby PJ, Blankenbiller T, et al. Effect of Fremanezumab compared with placebo for prevention of episodic migraine: A randomized controlled trial. JAMA. 2018 May;319(19):1999-2008. https://doi.org/10.1001/jama.2018.4853

19. Bigal ME, Edvinsson L, Rapoport AM, Lipton RB, Spierings EL, Diener HC, et al. Safety, tolerability, and efficacy of TEV-48125 for preventive treatment of chronic migraine: a multicentre, randomised, double-blind, placebo-controlled, phase 2b study. Lancet Neurol. 2015 Nov;14(11):1091-100. https://doi.org/10.1016/S1474-4422(15)00245-8

20. Silberstein SD, Dodick DW, Bigal ME, Yeung PP, Goadsby PJ, Blankenbiller T, et al. Fremanezumab for the preventive treatment of chronic migraine. N Engl J Med. 2017 Nov;377(22):2113-22. https://doi.org/10.1056/NEJMoa1709038

21. Stauffer VL, Dodick DW, Zhang Q, Carter JN, Ailani J, Conley RR. Evaluation of Galcanezumab for the Prevention of Episodic Migraine: The EVOLVE-1 Randomized Clinical Trial. JAMA Neurol. 2018 Sep;75(9):1080-8. https://doi.org/10.1001/jamaneurol.2018.1212

22. Skljarevski V, Matharu M, Millen BA, Ossipov MH, Kim BK, Yang JY. Efficacy and safety of galcanezumab for the prevention of episodic migraine: results of the EVOLVE-2 Phase 3 randomized controlled clinical trial. Cephalalgia. $2018 \mathrm{Jul}$;38(8):1442-54. https://doi.org/10.1177/0333102418779543

23. Dodick DW, Goadsby PJ, Silberstein SD, Lipton RB, Olesen J, Ashina M, et al. Safety and efficacy of ALD403, an antibody to calcitonin gene-related peptide, for the prevention of frequent episodic migraine: a randomised, double-blind, placebo-controlled, exploratory phase 2 trial. Lancet Neurol. 2014 Nov;13(11):1100-7. https://doi.org/10.1016/S1474-4422(14)70209-1 
24. SaperJR, Lipton RB, Kudrow DB, et al. A Phase 3, randomized, doubleblind, placebo-controlled study to evaluate the effectiveness and safety of Eptinezumab in frequent episodic migraine prevention: primary results of the PROMISE 1 (PRevention Of Migraine via Intravenous eptinezumab Safety and Efficacy 1) Trial. PO-01-194 [abstract]. Cephalalgia. 2017;37:337.

25. Kudrow D, Diamond M, McGill L, et al. Eptinezumab Achieved Meaningful Reductions in Migraine Activity as Early as Day 1 That Were Sustained Through Week 12: Results From PROMISE-2 (PRevention Of Migraine via Intravenous eptinezumab Safety and Efficacy-2) Phase 3 Trial in Chronic Migraine. P4-470. American Academy of Neurology meeting, April 2018 (abstract).

26. Tassorelli C, Diener HC, Dodick DW, Silberstein SD, Lipton RB, Ashina M, et al.; International Headache Society Clinical Trials
Standing Committee. Guidelines of the International Headache Society for controlled trials of preventive treatment of chronic migraine in adults. Cephalalgia. 2018 Apr;38(5):815-32. https://doi.org/10.1177/0333102418758283

27. Krymchantowski AV, da Cunha Jevoux C, Bigal ME. Topiramate plus nortriptyline in the preventive treatment of migraine: a controlled study for nonresponders. J Headache Pain. 2012 Jan;13(1):53-9. https://doi.org/10.1007/s10194-011-0395-4

28. Depre C, Antalik L, Starling A, Koren M, Eisele O, Lenz RA, et al. A Randomized, double-blind, placebo-controlled study to evaluate the effect of erenumab on exercise time during a treadmill test in patients with stable angina. Headache. 2018 May;58(5):715-23. https://doi.org/10.1111/head.13316 